\title{
Relationship between spontaneous echo contrast and hematological markers in patients with rheumatic mitral stenosis
}

\author{
Nermin Bayar ${ }^{\mathrm{a}, *}$, Zehra Erkal $^{\mathrm{a}}$, Selcuk Küçükseymen ${ }^{\mathrm{a}}$, Ramazan Güven ${ }^{\mathrm{b}}$, Şakir Arslan ${ }^{\text {a }}$ \\ a Antalya Education and Research Hospital, Cardiology Department, Antalya, Turkey \\ ${ }^{\mathrm{b}}$ Bitlis State Hospital, Emergency Medicine Department, Antalya, Turkey
}

\section{A R T I C L E I N F O}

\section{Article history:}

Received 27 April 2016

Received in revised form 8 June 2016

Accepted 10 June 2016

Available online 16 June 2016

\section{Keywords:}

Mitral stenosis

Spontaneous echo contrast

Platelet function

\begin{abstract}
A B S T R A C T
Introduction: Systemic thromboembolism is a serious morbidity and mortality cause for patients with rheumatic mitral stenosis (RMS). Previously conducted researches showed that spontaneous echo contrast (SEC) found in the left atrium can constitute a risk factor for thrombus formation. The aim of this study is to evaluate the role of echocardiographic and hematologic parameters in anticipating the presence of SEC in the left atrium of patients with moderate-severe RMS.

Methods: This retrospective study includes all patients who were diagnosed with moderate-severe RMS and underwent a transesophageal echocardiography between 2011 and 2014 . They were then divided in two groups depending on SEC presence; a SEC negative group and a SEC positive group.

Results: There were 33 patients (32\%) in the SEC negative group and 71 patients (68\%) in the SEC positive group. The mean platelet volume was found to be significantly higher in the SEC positive group ( $10.0 \pm 1.3 \mathrm{vs} .11 .6 \pm$ $1.4, \mathrm{p}<0.001)$. To identify the factors affecting the presence of SEC, a multivariate analysis of the hematologic parameters was conducted and the mean platelet volume was found to be an independent predictor (odds ratio $1.913,95 \%$ confidence interval $1.300-2.814 ; \mathrm{p}=0.001$ ). In the receiver operating characteristics curve analysis, a mean platelet volume $>11.8 \mathrm{fl}$ had a $55 \%$ sensitivity and $92 \%$ specificity in predicting SEC in patients with mitral stenosis.

Conclusion: Mean platelet volume constitutes an independent risk factor for the presence of left atrial SEC in patients with moderate-severe mitral valve stenosis.

(C) 2016 The Society of Cardiovascular Academy. Production and hosting by Elsevier B.V. All rights reserved. This is

an open access article under the CC BY-NC-ND license (http://creativecommons.org/licenses/by-nc-nd/4.0/).
\end{abstract}

\section{Introduction}

Especially in developing countries, rheumatic mitral stenosis (RMS) is still a major health concern. ${ }^{1}$ Patients with RMS show an elevated risk for systemic thromboembolism, which becomes a primary mortality and morbidity cause. ${ }^{2}$ Among the suggested mechanisms leading to the disease are autoimmunity, inflammation and increased thrombotic activity. $^{3-5}$

Spontaneous echo contrast (SEC) is the presence of smoke - like echoes with a characteristic swirling motion of blood found during echocardiography. ${ }^{6}$ Previously conducted researches showed that presence of SEC in the left atrium can constitute a risk factor for thrombus formation. ${ }^{7}$ In patients with RMS the risk of thrombosis and left atrial SEC development is eventually higher. ${ }^{8}$ The aim of this study is

\footnotetext{
* Corresponding author at: Antalya Education and Research Hospital, Cardiology Department, Muratpasa, 07100 Antalya, Turkey. Tel.: +90 505400 7509; fax: +90 242 2444900.

E-mail address: dr.nermin@mynet.com (N. Bayar).

Peer review under responsibility of The Society of Cardiovascular Academy.
}

to investigate the relationship between the presence of SEC and related hematologic parameters in patients with moderate-severe RMS.

\section{Methods}

In this retrospective study all moderate-severe RMS patients, who had a percutaneous mitral balloon valvuloplasty between 2011 and 2014 in our clinic were included (mitral valve area $<1.5 \mathrm{~cm}^{2}$ ). Their respective electrocardiograms were inspected and the rhythm defined.

The exclusion criteria for the present study were left atrial thrombus formation, significant mitral regurgitation (grade $>1$ ), other moderate or severe valve disease, history of malignancy, history of inflammatory disease, current therapy with corticosteroids, connective tissue disease, thyroid disease, other hematological disease and acute infectious disease. A medical history was recorded from patient anamnesis form.

Transesophageal echocardiography (TEE) and transthoracic echocardiography (TTE) records were also investigated (EPIQ 7 Ultrasound System, Philips, Heide, Netherlands). All the echocardiographic findings were carefully evaluated by two separate cardiologists. All measurements were taken according to the recommendations of the American Society of Echocardiography. ${ }^{9}$ The mean value of 3 measurements was 
taken from patients with sinus rhythm and the mean value of 7 measurements from patients with atrial fibrillation. Routine echocardiographic measurements were also recorded. The planimetric measurements of the mitral valve area were also conducted. The mitral valve was assessed by TEE. The Wilkins score was determined by rating the severity of leaflet mobility, leaflet thickening, leaflet calcification and subvalvular thickening with a score of $0-4$ and then adding the results together. ${ }^{10}$ Left atrial SEC presence and degree was asses by TEE according to the criteria laid down by Fatkin et al. ${ }^{11}$ The patients were then divided into two groups; a SEC positive group and a SEC negative one.

On the TEE day, the patients had blood drown from the antecubital vein and underwent routine biochemistry and complete blood count (CBC) tests, after a 12 hour fast. CBC including white blood cell (WBC), neutrophil and lymphocyte counts, mean platelet volume (MPV, normal range: 7.4-10.4 fl) were done using an automatized $C B C$ count device (Abott Cell Dyn, Illinois USA). The C-reactive protein (CRP) levels (normal range: $0-5 \mathrm{mg} / \mathrm{L}$ ) were analyzed with a Beckman Coulter Inc. (Image 800, California, USA).

\section{Statistical analysis}

Data were analyzed with the SPSS software version 21.0 for Windows (SPSS Inc., Chicago, IL, USA). Continuous variables were expressed as mean $+\mathrm{SD}$, and categorical variables are expressed as percent. The $\chi^{2}$ test and Fisher's exact test were used to compare categorical variables. The Shapiro-Wilk test was used to assess the distribution of continuous variables. Student's t-test was used for variables with normal distribution and the values were presented as mean \pm SD. Continuous variables without normal distribution were analyzed using Mann-Whitney U test. Receiver operating characteristic (ROC) curve analysis was performed to identify optimal cutoff values for MPV. The effects of different variables on SEC were calculated in univariate analysis for each. The variables for which the unadjusted P-value was 0.10 in logistic regression analysis were identified as potential risk markers and included in the full model. The odds ratios (OR) and 95\% confidence intervals ( $\mathrm{CI}$ ) were calculated. A two-tailed $\mathrm{p}$-value of $<0.05$ was considered statistically significant.

\section{Results}

104 patients were included in this study of which $80(77 \%)$ were female. 33 of them (32\%) were in the SEC negative group (mean age $43.6+14.5$ ) and $71(68 \%)$ in the SEC positive group (mean age $47.0+11.3$ ). Mean age, diabetes mellitus, hypertension, hyperlipidemia presence and aspirin or warfarin usage was similar among the groups. Atrial fibrillation (AF) was detected in 11 (33\%) of the SEC negative group patients and $28(40 \%)$ in the SEC positive one $(\mathrm{p}=$ 0.634). Also, in 31 of the 39 patients who had AF (79\%) and in 48 of the 65 patients who did not have AF (73\%), SEC presence was detected ( $p=0.632$ ). The groups' baseline characteristics are shown in Table 1.

The Wilkins score $(9.6 \pm 2.8$ vs. $7.0 \pm 2.2, \mathrm{p}<0.001)$ and the left atrial diameter $(46.3 \pm 2.7 \mathrm{~mm}$ vs. $44.7 \pm 2.2 \mathrm{~mm}, \mathrm{p}=0.010)$ were found to be significantly higher in the SEC positive group. There was no significant difference among groups with regard to the mitral valve area $(1.0+0.2$ vs. $1.1+0.2, \mathrm{p}=0.423)$. TTE and TEE findings are shown in Table 2.

There was no significant difference among the groups with respect to some hematologic parameters like WBC count, platelet count, red cell distribution width and CRP (Table 3). However, MPV (11.6 \pm 1.4 vs $10.0 \pm 1.3, \mathrm{p}<0.001)$ was found to be significantly higher in the SEC positive group (Fig. 1). A univariate logistic regression analysis was performed in order to determine the factors leading to SEC presence and MPV (OR $=1.972,95 \% \mathrm{CI}: 1.411-2.758 ; \mathrm{p}<0.001)$, Wilkins score (OR $=1.409,95 \% \mathrm{CI}: 1.172-1.693, \mathrm{p}<0.001)$ and left atrial diameter $(\mathrm{OR}=1.265,95 \% \mathrm{CI}: 1.051-1.522 ; \mathrm{p}=0.013)$ were
Table 1

Demographic characteristics of the groups according to the SEC presence.

\begin{tabular}{|c|c|c|c|}
\hline \multirow{2}{*}{ Variable } & \multirow{2}{*}{$\frac{\text { SEC negative }}{(\mathrm{n}=33)}$} & \multirow{2}{*}{$\frac{\text { SEC positive }}{(\mathrm{n}=71)}$} & \multirow{2}{*}{ P value } \\
\hline & & & \\
\hline Age, years & $43.6 \pm 14.5$ & $47.0 \pm 11.3$ & 0.286 \\
\hline Female, n (\%) & $28(84 \%)$ & $52(73 \%)$ & 0.062 \\
\hline DM, n (\%) & $3(11.5 \%)$ & $13(16.7 \%)$ & 0.755 \\
\hline Hypertension, n (\%) & $11(42.3 \%)$ & $37(47.4 \%)$ & 0.650 \\
\hline $\mathrm{TC}, \mathrm{mg} / \mathrm{dl}$ & $189.0 \pm 42.9$ & $184.3 \pm 36.5$ & 0.417 \\
\hline LDL, mg/dl & $125.5 \pm 34.5$ & $115.0 \pm 34.6$ & 0.106 \\
\hline $\mathrm{HDL}, \mathrm{mg} / \mathrm{dl}$ & $45.0 \pm 9.3$ & $42.2 \pm 8.3$ & 0.119 \\
\hline Trygliceride, mg/dl & $98.9 \pm 43.3$ & $122.2 \pm 59.1$ & 0.072 \\
\hline $\mathrm{AF}, \mathrm{n}(\%)$ & $11(33 \%)$ & $28(40 \%)$ & 0.634 \\
\hline Aspirin, n (\%) & $17(51 \%)$ & $38(53 \%)$ & 0.248 \\
\hline Warfarin, n (\%) & $12(38 \%)$ & $29(41 \%)$ & 0.228 \\
\hline Beta blocker, n (\%) & $16(48 \%)$ & $36(51 \%)$ & 0.728 \\
\hline
\end{tabular}

(Data are expressed as mean \pm standard deviation for normally distributed data and percentage for categorical variables).

(AF: atrial fibrillation, DM: diabetes mellitus, HDL: high density lipoprotein, LDL: low density lipoprotein, TC: total cholesterol).

shown to be risk factors. Also, a multivariate logistic regression analysis was performed in order to determine the factors leading to SEC presence and MPV value was found to be an independent predictor ( $\mathrm{OR}=1.913,95 \% \mathrm{CI}: 1.300-2.814, \mathrm{p}=0.001$ ) (Table 4). In the ROC curve analysis, a MPV > $11.8 \mathrm{fl}$ had a $55 \%$ sensitivity and $92 \%$ specificity in predicting SEC in patients with mitral stenosis (area under the curve 0.780, $\mathrm{p}<0.001$ )(Fig. 2).

\section{Discussion}

Patients with moderate-severe RMS were included in this study and $23 \%$ of them were found to have SEC presence in their left atrium. Univariate and multivariate analysis showed that Wilkins echo score, MPV and left atrium diameter were risk factors related to left atrial SEC presence. In addition to that, MPV $>11.8 \mathrm{fl}$ was found to have a $55 \%$ sensitivity and $92 \%$ specificity in predicting SEC presence in patients with mitral stenosis.

SEC is a dynamic smoke-like echo with a characteristic swirling motion of blood detected by echocardiography. ${ }^{12}$ In RMS patients there is an increase in general inflammatory and prothrombotic state and therefore the risk of stasis in the left atrium that will eventually lead to left atrial SEC or thrombus, is significantly higher than the normal population. ${ }^{13,14}$ In previous studies SEC was found to have a frequency of 21-67\% in RMS patients and systemic thromboembolism was reported as an independent predictor of SEC presence. ${ }^{6,15,16}$ Some

\section{Table 2}

Echocardiographic characteristics of the groups according to the SEC presence (variables with normal distribution were expressed as mean \pm SD).

\begin{tabular}{|c|c|c|c|}
\hline \multirow{2}{*}{ Variable } & \multirow{2}{*}{$\frac{\text { SEC negative }}{(\mathrm{n}=33)}$} & \multirow{2}{*}{$\frac{\text { SEC positive }}{(\mathrm{n}=71)}$} & \multirow{2}{*}{ P value } \\
\hline & & & \\
\hline LVEF, \% & $62.1 \pm 4.2$ & $62.0 \pm 4.4$ & 0.682 \\
\hline LA diameter, mm & $44.7 \pm 2.2$ & $46.3 \pm 2.7$ & 0.010 \\
\hline LAVI, $\mathrm{ml} / \mathrm{m}^{2}$ & $32.1 \pm 8.2$ & $33.4 \pm 7.2$ & 0.378 \\
\hline LVEDD, mm & $44.0 \pm 4.0$ & $46.1 \pm 5.0$ & 0.128 \\
\hline LVESD, mm & $28.3 \pm 4.4$ & $30.1 \pm 5.0$ & 0.090 \\
\hline MVA, $\mathrm{cm}^{2}$ & $1.1 \pm 0.2$ & $1.0 \pm 0.2$ & 0.423 \\
\hline Peak gradient, mm Hg & $24.5 \pm 9.2$ & $21.9 \pm 7.7$ & 0.679 \\
\hline Mean gradient, mm Hg & $14.5 \pm 6.2$ & $13.1 \pm 6.2$ & 0.317 \\
\hline WS & $7.0 \pm 2.2$ & $9.6 \pm 2.8$ & $<0.001$ \\
\hline Valve mobility & $1.7 \pm 0.6$ & $2.4 \pm 0.7$ & $<0.001$ \\
\hline Subvalvular & $1.6 \pm 0.6$ & $2.4 \pm 0.9$ & $<0.001$ \\
\hline Valve thickness & $1.9 \pm 0.7$ & $2.5 \pm 0.8$ & 0.004 \\
\hline Calcification & $1.7 \pm 0.9$ & $2.3 \pm 0.9$ & 0.010 \\
\hline sPAP, mm Hg & $43.9 \pm 13.4$ & $40.7 \pm 8.7$ & 0.365 \\
\hline
\end{tabular}

(LA: left atrium, LAVI: left atrial volume index, LVEF: left ventricular ejection fraction, LVEDD: left ventricular end diastolic diameter, LVESD: left ventricular end systolic diameter, MVA: mitral valve area, SEC: spontaneous echo contrast, WS: Wilkins score). 
Table 3

Common hemogram and inflammatory parameters of the groups according to the SEC presence.

\begin{tabular}{|c|c|c|c|}
\hline \multirow{2}{*}{ Variable } & SEC negative & SEC positive & \multirow{2}{*}{ P value } \\
\hline & $(n=33)$ & $(n=71)$ & \\
\hline Hemoglobin, g/dl & $12.2 \pm 1.2$ & $13.0 \pm 1.3$ & 0.023 \\
\hline $\mathrm{WBC},\left(\times 10^{3} / \mu \mathrm{L}\right)$ & $7.8 \pm 2.0$ & $7.9 \pm 2.3$ & 0.892 \\
\hline Platelet count, $\left(\times 10^{3} / \mu \mathrm{L}\right)$ & $221.2 \pm 69.3$ & $236.6 \pm 59.9$ & 0.276 \\
\hline MPV, fl & $10.0 \pm 1.3$ & $11.6 \pm 1.4$ & $<0.001$ \\
\hline RDW, \% & $15.2 \pm 2.2$ & $14.4 \pm 1.9$ & 0.073 \\
\hline CRP, mg/l & $6.1 \pm 5.5$ & $6.1 \pm 5.2$ & 0.703 \\
\hline
\end{tabular}

Variables with normal distribution were expressed as mean \pm SD.

CRP: C-reactive protein, MPV: mean platelet volume, RDW: red blood cell distribution width, WBC: white blood cells count.

of the reported clinic and echocardiographic risk factor of SEC in RMS patients are atrial fibrillation, high Wilkins score, small mitral valve area, increased mitral gradient, left atrial dilation without severe mitral insufficiency. ${ }^{4,17}$ In a similar way, our study found that Wilkins score was significantly higher in the SEC positive group, but couldn't find a significant association with mitral valve area and mitral gradient.

The pathophysiological mechanism of RMS is related to the antigenic similarity of the streptococcal M protein with cardiac tissue and to the related autoimmune response that follows. In the chronic state of the disease, inflammation is persistent even without the presence of an infectious agent. ${ }^{3,18}$ According to previous studies, inflammatory predictors were found to be elevated in RMS patients. ${ }^{4,19}$ Kaya et al. studied the systemic inflammatory state predictors in RMS patients with SEC presence and reported significantly elevated values of high sensitive CRP and neutrophil/lymphocyte ratio. Also, a neutrophil/lymphocyte ratio $>3.1$ was found to have a specificity of $72 \%$ and a sensitivity of $80 \%$ in detecting left atrial SEC presence in this study. ${ }^{20}$

Increased prothrombotic state has also been reported, alongside increased inflammation, in RMS patients. Previous studies have reported increased MPV, P-selectin, fibrinogen and D-dimer levels as conditions related to the increased prothrombotic state in these patients. ${ }^{5,21,22}$ It has also been shown that MPV values, in RMS patients, tend to decrease after percutaneous mitral balloon valvuloplasty. ${ }^{22} \mathrm{MPV}$ is one of the indicators of platelet function. Bigger platelets are hemostatically more reactive that smaller ones and an increase in MPV values, reflect an increase in platelet function. ${ }^{23-25}$ Akpek et al. included 232 RMS patients in their study and found that MPV values were correlated to left atrial SEC presence and SEC degree. ${ }^{14}$ In a study conducted by Illeri et al., examined 84 patients with RMS, severe MR and left atrium SEC presence have been shown to be associated with increased in MPV. ${ }^{26}$

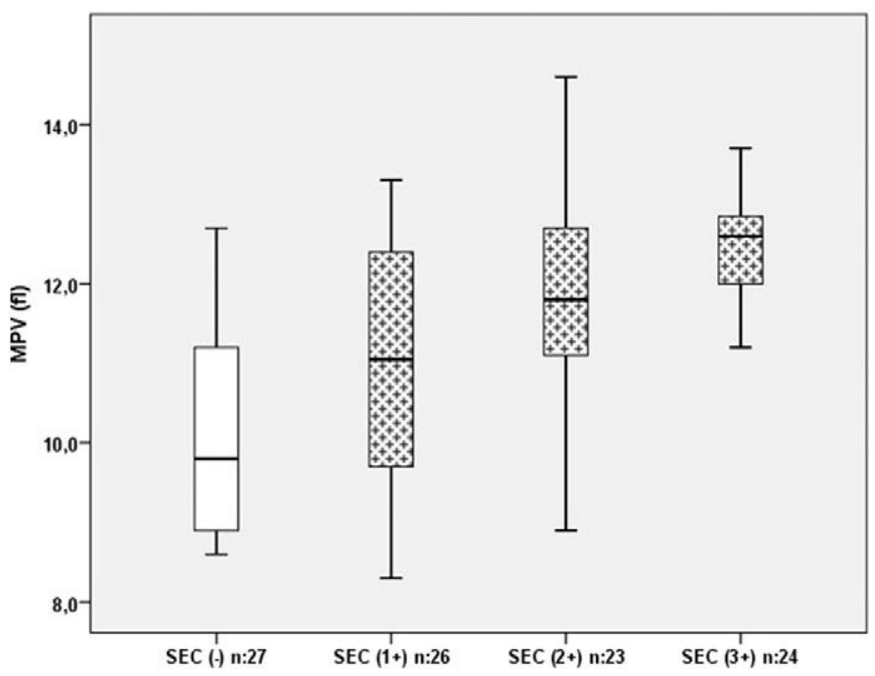

Fig. 1. MPV levels in the SEC negative and SEC positive patients.
Table 4

Evaluation of the factors affecting the presence of the SEC by univariate and multivariate logistic regression analysis.

\begin{tabular}{|c|c|c|c|c|}
\hline \multirow[b]{2}{*}{ Variable } & \multicolumn{2}{|l|}{ Univariate } & \multicolumn{2}{|l|}{ Multivariate } \\
\hline & OR (95\% CI) & P value & Adjusted OR (95\%CI) & P value \\
\hline Sex & $0.123(0.016-0.959)$ & 0.046 & & \\
\hline Hemoglobin & $1.552(1.072-2.246)$ & 0.020 & $1.424(0.950-2.134)$ & 0.087 \\
\hline MPV & $1.972(1.411-2.758)$ & $<0.001$ & $1.913(1.300-2.814)$ & 0.001 \\
\hline RDW & $0.835(0.677-1.031)$ & 0.093 & & \\
\hline CRP & $0.996(0.919-1.079)$ & 0.926 & & \\
\hline Trygliceride & 1.009 (0.999-1.019) & 0.072 & & \\
\hline LA diameter & $1.265(1.051-1.522)$ & 0.013 & 1.007 (0.997-1.017) & 0.026 \\
\hline WS & $1.409(1.172-1.693)$ & $<0.001$ & $1.345(1.092-1.657)$ & 0.005 \\
\hline LVEF & $9.992(0.894-1.100)$ & 0.876 & & \\
\hline LVESD & $1.126(1.018-1.246)$ & 0.022 & & \\
\hline Mean gradient & $0.967(0.903-1.036)$ & 0.335 & & \\
\hline MVA & $0.418(0.050-3.476)$ & 0.420 & & \\
\hline
\end{tabular}

CRP: C-reactive protein, LA: left atrium, LVEF: left ventricle ejection fraction, MPV: mean platelet volume, MVA: mitral valve area, RDW: red blood cell distribution width, WS: Wilkins score.

In a similar way, our study found that MPV values were higher in SEC positive patients, compared to SEC negative patients. In addition to this, our study found that a MPV > 11.8 fl value was an independent predictor of SEC presence.

Atrial fibrillation is an important risk factor for the development of left atrial SEC or thrombus. ${ }^{7}$ In addition to patients with AF, previous studies have reported an increased hypercoagulable state in RMS patients with sinus rhythm too. ${ }^{27}$ Risk factors associated with left atrial thrombus are advanced age, atrial fibrillation, small mitral valve area, dilated left atrium and SEC presence. ${ }^{17,28}$ Munjunath et al. studied 848 RMS patients with sinus rhythm and reported that left atrial thrombus did not form without a SEC presence. ${ }^{27}$ Therefore it is important to detect SEC positive patients. Our study did not detect any significant difference among the groups with respect to atrial fibrillation but reported increased MPV values as independent predictors of SEC presence. Despite being on sinus rhythm, patients with MPV $>11.8 \mathrm{fl}$ had a higher probability of developing SEC and therefore should be regularly monitored with TEE. To investigate the need and effectiveness of

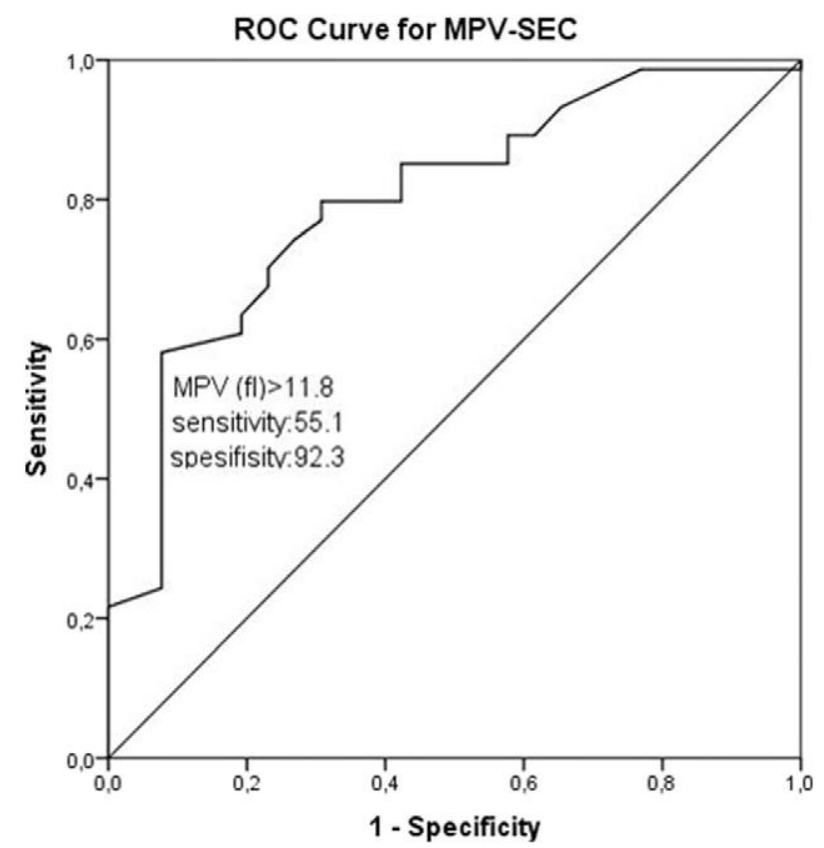

Fig. 2. ROC curve analysis for MPV in prediction of SEC (area under the curve 0.780, $\mathrm{p}<0.001)$. 
anti-inflammatory, antiplatelet and anticoagulant therapy in these patients, large randomized trials results are needed.

\section{Study limitations}

This study was a retrospective one. The possible limitations of the present study include that it was a single-center experience and included a small number of patients. Possibility of intermittent atrial fibrillation cannot be ruled out. Measures of thromboembolic risk like left atrial appendage size, and filling and emptying velocities were not studied. Because the majority of the included patients were expecting a percutaneous mitral balloon valvuloplasty, those with severe mitral insufficiency were not included. Therefore these results may not represent patients with severe mitral insufficiency.

\section{Conclusion}

Independently from cardiac rhythm, MPV value was found to be independently related to left atrial SEC presence in RMS patients.

\section{Conflict of interest}

None declared.

\section{References}

1. Soler-Soler J, Galve E. Worldwide perspective of valve disease. Heart 2000;83: 721-725.

2. Fukuda Y, Nakamura K. The incidence of thromboembolism and the hemocoagulative background in patients with rheumatic heart disease. Jpn Circ J 1984;48:59-66.

3. Guilherme L, Cunha-Neto E, Coelho V, et al. Human heart-infiltrating T-cell clones from rheumatic heart disease patients recognize both streptococcal and cardiac proteins. Circulation 1995;92:415-420.

4. Alyan O, Metin F, Özdemir Ö, et al. High levels of high sensitivity C-reactive protein predict the progression of chronic rheumatic mitral stenosis. J Thromb Thrombolysis 2009;28:63-69.

5. Hasan-Ali H, Mosad E. Changes in platelet, coagulation and fibrinolytic activities in mitral stenosis after percutaneous mitral valvotomy: role of hemodynamic changes and systemic inflammation. Clin Appl Thromb Hemost 2015;21:339-347.

6. Beppu S, Nimura Y, Sakakibara H, et al. Smoke-like echo in the left atrial cavity in mitral valve disease: its features and significance. J Am Coll Cardiol 1985;6:744-749.

7. Black IW, Hopkins AP, Lee LC, et al. Left atrial spontaneous echo contrast: a clinical and echocardiographic analysis. J Am Coll Cardiol 1991;18:398-404.

8. Rittoo D, Sutherland GR, Currie P, et al. A prospective study of left atrial spontaneous echo contrast and thrombus in 100 consecutive patients referred for balloon dilatation of the mitral valve. J Am Soc Echocardiogr 1994;7:516-527.

9. Daniel WG, Nellesen U, Schroder E, et al. Left atrial spontaneous echo contrast in mitral valve disease: an indicator for an increased thromboembolic risk. J Am Coll Cardiol 1988;11:1204-1211.
10. Wilkins GT, Weyman AE, Abascal VM, et al. Percutaneous balloon dialatation of the mitral-valve - an analysis of echocardiographic variables related to outcome and the mechanism of dilatation. Br Heart J 1988;60:299-308.

11. Fatkin D, Kelly R, Feneley MP. Left atrial appendage blood velocity and thromboembolic risk in patients with atrial fibrillation. J Am Coll Cardiol 1994;24:1429-1430.

12. Merino A, Hauptman P, Badimon L, et al. Echocardiographic 'smoke' is produced by an interaction of erytrocytes and plasma proteins modulated by shear forces. J Am Coll Cardiol 1992;20:1661-1668.

13. Karthikeyan G, Thachil A, Sharma S, et al. Elevated high sensitivity CRP levels in patients with mitral stenosis and left atrial thrombus. Int J Cardiol 2007;122:252-254

14. Akpek M, Kaya MG, Yarlioglues M, et al. Relationship between platelet indices and spontaneous echo contrast in patients with mitral stenosis. Eur J Echocardiogr 2011;12:865-870.

15. Ozkan M, Kaymaz C, Kırma C, et al. Predictors of left atrial clot and spontaneous echo contrast in rheumatic valve disease before and after mitral valve replacement. Am J Cardiol 1998;82:1066-1070.

16. Vigna C, de Rito V, Criconia GM, et al. Left atrial clot and spontaneous echo contrast in nonanticoagulated mitral stenosis. A transesophageal echocardiography study. Chest 1993:103:348-352.

17. Drissi S, Sabor H, Ounsy A, et al. Predictive factors of left atrial spontaneous echo contrast in patients with rheumatic mitral valve stenosis: a retrospective study of 159 patients. Int Arch Med 2014;7:32.

18. Cunningham MW. T cell mimicry in inflammatory heart disease. Mol Immunol 2004;40:1121-1127.

19. Polat N, Ylldız A, Yuksel M, et al. Association of neutrophil-lymphocyte ratio with the presence and severity of rheumatic mitral valve stenosis. Clin Appl Thromb Hemost 2014;20:793-798.

20. Kaya MG, Akpek M, Elcik D, et al. Relation of left atrial spontaneous echocardiographic contrast in patients with mitral stenosis to inflammatory markers. Am J Cardiol 2012;109:851-855.

21. Yavuz B, Ertuğrul DT, Yalçın AA, et al. Increased mean platelet volume in rheumatic mitral stenosis: a possible factor for thromboembolic events. J Cardiol 2009;53: 204-207.

22. Kataoka H, Yano S, Tamura A, et al. Hemostatic changes induces by percutaneous mitral valvuloplasty. Am Heart J 1993;125:777-782.

23. Thompson CB, Eaton KA, Princiotta SM, et al. Size dependent platelet subpopulations: relationship of platelet volume to ultrastructure, enzymatic activity, and function. $\mathrm{Br} J$ Haematol 1982;50:509-519.

24. Haver VM, Gear AR. Functional fractionation of platelets. J Lab Clin Med 1981;97: 187-204.

25. Martin JF, Trowbridge EA, Salmon G, et al. The biological significance of platele volume: its relationship to bleeding time, platelet thromboxane B2 production and megakaryocyte nuclear DNA concentration. Thromb Res 1983;32:443-460.

26. Ileri M, Kanat S, Gürsoy HT, et al. Increased mean platelet volume in rheumatic mitral stenosis: assessment of clinical and echocardiographic determinants. Kardiol Pol 2015;73:46-53.

27. Manjunath CN, Srinivasa KH, Panneerselvam A, et al. Incidence and predictors of left atrial thrombus in patients with rheumatic mitral stenosis and sinus rhythm: a transesophageal echocardiographic study. Echocardiography 2011;28:457-460.

28. Goswami KC, Yadav R, Rao MB, et al. Clinical and echocardiographic predictors of left atrial clot and spontaneous echo contrast in patients with severe rheumatic mitral stenosis: a prospective study in 200 patients by transesophageal echocardiography Int J Cardiol 2000;73:273-279. 